\title{
Identifying areas for linkages between HIV and SRH for vulnerable populations: An exploratory study to assess female sex workers' sexual and reproductive health needs
}

Vaishali Sharma Mahendra

Sushma Mehrotra

B. Srikanthi

Sucheta Panda

Avina Sarna

Population Council

See next page for additional authors

Follow this and additional works at: https://knowledgecommons.popcouncil.org/departments_sbsr-hiv

Part of the Demography, Population, and Ecology Commons, Family, Life Course, and Society Commons, Gender and Sexuality Commons, International Public Health Commons, and the Medicine and Health Commons How does access to this work benefit you? Let us know!

\section{Recommended Citation}

Mahendra, Vaishali Sharma, Sushma Mehrotra, B. Srikanthi, Sucheta Panda, Avina Sarna, A.K. Jayasree, Rajendra Prasad, and Naomi Rutenberg. 2007. "Identifying areas for linkages between HIV and SRH for vulnerable populations: An exploratory study to assess female sex workers' sexual and reproductive health needs," Research update. New Delhi: Population Council. 


\section{Authors}

Vaishali Sharma Mahendra, Sushma Mehrotra, B. Srikanthi, Sucheta Panda, Avina Sarna, A.K. Jayasree, Rajendra Prasad, and Naomi Rutenberg 

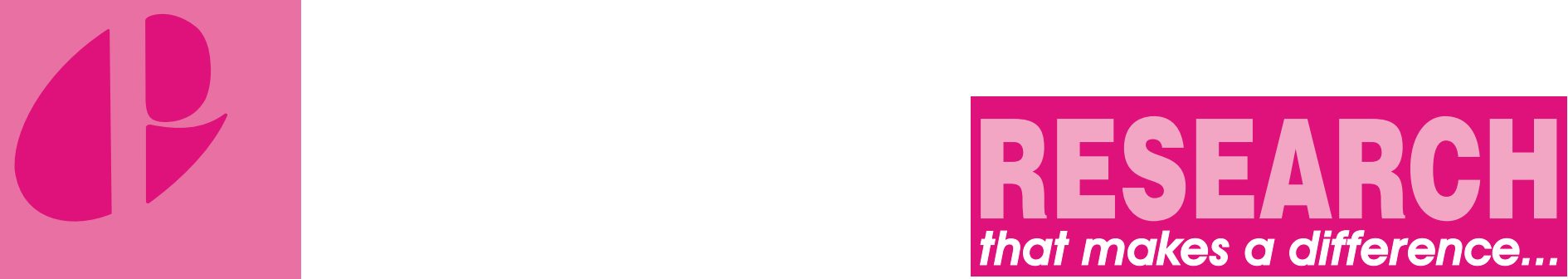

\section{Identifying areas for linkages between HIV and SRH for vulnerable populations: An exploratory study to assess female sex workers' sexual and reproductive health needs}

\section{Background}

It is well recognized that sexual and reproductive (SRH) ill-health and HIV/AIDS share root causes, including poverty, gender inequality and social marginalization of the most vulnerable populations. This has prompted the international community to call for policy and program approaches to strengthen the linkages between SRH and HIV/AIDS programmes. However, most integration efforts have given priority to family planning, maternal and child health and STI treatment as well as to addressing the needs of married women from the 'general population'. Female sex workers have been targeted for HIV prevention efforts but little attention has been given to SRH-related care for them. To bring sex workers into the focus for SRH-HIV convergence, it is important to understand their SRH needs, explore approaches that can be adopted by existing HIV programs to meet these needs and examine if current services can be geared to provide these services. Population Council, in collaboration with CARE-India conducted an exploratory research study to understand sex workers' SRH needs and health seeking behaviour to suggest areas and strategies for linkages with HIV.

\section{Study Methodology}

\section{Study sites}

The exploratory study was undertaken with brotheland non-brothel-based sex workers in the East Godavari district of Andhra Pradesh. The district is estimated to have one of the highest HIV-prevalence in the state. In this district, the towns of Rajahmundry and Kakinada were selected as the study locations owing to the presence of two NGOs-CARE India in Rajahmundry and CHANGES in Kakinada-that are implementing HIV and STI prevention programs with sex workers.

\section{Study design}

The cross-sectional study design involved collection of qualitative and quantitative data from
August 2006 to January 2007. In-depth interviews were conducted with $35 \mathrm{HIV}$-positive sex workers and pregnant sex workers to understand their needs for HIV treatment and SRH care and health seeking behaviour. In addition, 17 interviews were conducted with service providers, brothel heads, peer leaders to explore the structural factors that influence sex workers' access to information and services. Also, five group discussions were held with 30-40 sex workers to understand community practices and perceptions regarding SRH and HIV care. This was followed by a survey of 348 sex workers representing brothel-based, householdbased and mobile sex workers. The sex workers were randomly selected from a list of sex workers enrolled by CARE and CHANGES in their prevention efforts. Interviews with sex workers were conducted following two-stage informed consent process to ensure voluntary participation and confidentiality of study participants.

The data were collected by the research team that comprised of social science researchers and field researchers, the latter represented the sex worker community. The field researchers underwent intensive training in research methodology and were engaged in design of the interview guides and survey questionnaire as well as in data collection.

This summary focuses on findings from interviews and survey with sex workers.

\section{Profile of sexworkers}

The median age of sex workers across the three groups - brothel-based, home-based and mobile sex workers - was 30 years. Over half of the brothelbased and mobile sex workers were either separated or deserted by their husbands or were widowed. In contrast, one-third of the home-based sex workers were separated/widowed, one-third were single and one-third were currently married. While the majority of all sex workers had no education, there were some differences across the groups. One-third of brothel- and home-based sex 
workers had up to 5 years of schooling as compared to one-fifth of mobile sex workers. When asked about their living conditions, close to half of the home-based sex workers reported living in their own home while the majority of brothelbased and mobile sex workers reported living in a rented house.

\section{Key Findings}

Deserted or separated from husband and need to earn a livelihood the key reason for entering into sexwork

According to the large majority of sex workers, the main reason for entering sex work was to earn an income for providing economic support to family, including parents and children. Over half of all sex workers earned between Rs 3000 and 5000 monthly from sex work.

"My husband left me shortly after marriage so I got into this work to support myself and my family."

(28 year old, mobile sex worker)

A little over one-tenth of the mobile sex workers mentioned they were sold or lured or forced into sex work and close to one-fifth of the home-based sex workers entered sex work as it was their 'family tradition'.

Figure 1: Sex workers report reasons for starting/entering into sex work

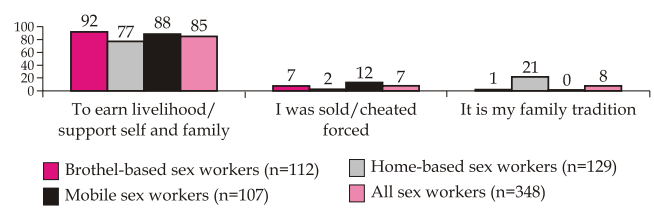

Almost all sex workers report consistent condom use with clients but not with intimate regular partners

Nearly all (97 percent) sex workers mentioned they used condoms consistently (always used condoms with all clients and used condom last time they had sex) with their clients for vaginal sex. Of the sex workers who had lovers or 'temporary husbands' $(n=226)$, only half reported consistent condom use. The married sex workers $(n=69)$ reported even lower use of condoms consistently with their husbands (only one-fourth of 69 currently married sex workers). The reasons for not using condoms with lover and husband was mainly to show 'him that I love him and trust him', 'I am afraid he will leave me if I insist', and 'he doesn't like condoms'.

"I used to use condoms with him earlier but not now... I love him and have faith in him that he doesn't have any other partner."

(20 year old,

HIV-negative pregnant sex worker)
In contrast, almost all the HIV-positive sex workers interviewed mentioned using condoms with their regular partners as well, as they did not want to transmit their infection to their partners.

"Lover means emotionally I have an attachment but physically I treat him like any other person. Why means I am already positive. So I do not want him to get it through me. Actually I take more care with my lover ... he is not even married and if he gets it then it will be difficult. He will spoil his life. So I take more care when it comes to him."

(22 year old, HIV-positive sex worker)

One-tenth of the sex workers reported anal sex with customers and lovers. They mentioned using condoms almost all the time with both the customers and lovers. When asked about use of any lubricant during anal sex, almost all mentioned use of coconut oil.

Majority of sex workers mention accessing health services for pregnancy- and delivery-related care but one-third deliver at home

Over half the respondents reported they had 2-3 pregnancies with a mean number of pregnancies equalling 2.39. Of the women who ever had a pregnancy $(n=326)$, a little over half were younger than 18 years of age when they had their first pregnancy and one-third were $18-20$ years old.

When sex workers were asked about care during their last pregnancy $(n=291), 55$ percent reported accessing ante-natal care from a public health facility and 42 percent mentioned the private sector with a very small minority choosing home-based care. Among the sex workers, the majority of home-based sex workers preferred to use the private services as compared to only one-fourth of the brothel-based and one-third of the mobile sex workers. The main reason for accessing public sector facilities during ANC was that the service was not costly and was affordable. Whereas, the home-based sex workers opted for 'better' quality services at expensive private health facilities.

Of the sex workers who had their last pregnancy after sex work $(n=162), 85$ percent mentioned continuing to do sex work during pregnancy. Of these sex workers, over half continued to practice sex work till the third trimester of pregnancy. Only 34 percent of sex workers mentioned using condoms with either their customer or lover or husband during their pregnancy. Some of the sex workers felt that 'doing sex in last trimester of pregnancy will help in making the delivery of the child easier'.

For delivery-related practice, a little less than half of the sex workers reported they had their last delivery in a public sector hospital and one-third mentioned at home. Home-based sex workers 
were more likely to have their delivery in private hospitals as compared to others.

\section{Unplanned pregnancies and utilization of services for abortion}

While the majority of sex workers mentioned their last pregnancy was planned, there were one-fifth $(n=55)$ who said otherwise. Of these, 28 sex workers said they wanted to end their pregnancy and the majority of them (21 of 28) reported they had an abortion. Most of them had the abortion in a private hospital or clinic followed by 'at home' and lastly in a public hospital. At home, the methods commonly used were massage by a dai or a medicine bought from the local chemist. Following the abortion, most of the women mentioned that they had some complications such as prolonged bleeding and severe abdominal pain. Most of the sex workers mentioned that they started sex work within a month of their abortion.

\section{Sterilization is the main family planning method adopted by sexworkers}

Of all the women, only 14 percent said they wanted to have a child and the rest did not. There were no differences among the three groups of sex workers. Most of the women said that as they already had at least one or two children, they did not want another one as they had enough financial burden and with no one else to 'support' them they could not 'afford' to have another child.

Of those sex workers who did not want children $(n=299)$, overall 83 percent reported using a method to prevent future pregnancy. Among the sex workers, the larger proportion of mobile ( 93 percent) and brothel-based (83 percent) sex workers reported using a family planning method as compared to 75 percent of home-based sex workers. When asked about the methods used by them for preventing pregnancies, the largest proportion (81 percent) mentioned they had undergone 'tubectomy' or sterilization. Of the sex workers who had undergone sterilization $(n=202)$, only one-fourth mentioned using condoms as dual method to protect against infections.

\section{Self-reported gynaecological morbidity among sex workers is high}

Sex workers were asked to list the common gynaecological health problems they suffered in the last one year. The four most commonly mentioned signs and symptoms included low abdominal pain (63 percent), low back pain (62 percent), foul smelling and discoloured vaginal discharge (44 percent), and pain during intercourse (42 percent). Most of the women reported suffering from at least 2-3 concurrent symptoms. Few women also mentioned they were diagnosed with cancerous growth or fibroids in their uterus and had undergone a hysterectomy by the time they were in their early 30 s.
The majority of the women who suffered from these health problems reported seeking treatment. Most mentioned seeking treatment from the NGO clinic followed by government hospital and then private clinic. The reasons for accessing these services were that the health facility was close to their home or that it was cheap and affordable and some mentioned they trusted the service provider.

Over half of the sex workers continued to practice sex work during the time they had these problems but mentioned they always used condoms with their partners. At the same time, a little less than half also said that they abstained from sex work till their symptoms were cured.

High uptake of HIV testing and counselling services but information and access to HIV treatment and care services is low

Awareness about modes of HIV transmission and methods of prevention was very high among all groups of sex workers. At the same time, myths and misconceptions were also prevalent. Also, over one-third of sex workers felt that HIV transmission risk can be reduced by washing or douching vagina after sex. As a result, over 90 percent of sex workers mentioned they wash their vagina with water mixed with dettol or soda or turmeric after sex.

Most sex workers felt they were at high risk of HIV infection owing to their work. This perception of risk prompted the majority (70 percent) of them to get tested for HIV. However, only half of the homebased sex workers reported ever getting an HIV test. The majority of sex workers reported they have got tested for HIV more than once. The HIV test facility accessed by most of the sex workers was the government testing centres. The sex workers mentioned that they were referred to the government facilities by the NGO. Almost all reported their consent was taken, 77 percent received pre-test counselling but only 60 percent reported getting post-test counselling.

The majority of sex workers had heard of services for prevention of parent-to-child transmission (PPTCT) and antiretroviral treatment (ART) but did not know the name of the medicines. However, in detailed discussion, it was evident that most sex workers confused ART with treatment for opportunistic infections. Some of the HIV-positive sex workers mentioned that as the ART centre was located in another town they did not go there as it meant 'wasting' time that they can spend in working and earning money. Another sex worker mentioned that the counsellor at one of the ART centres told her that it was futile to have medicines as she would die in a year.

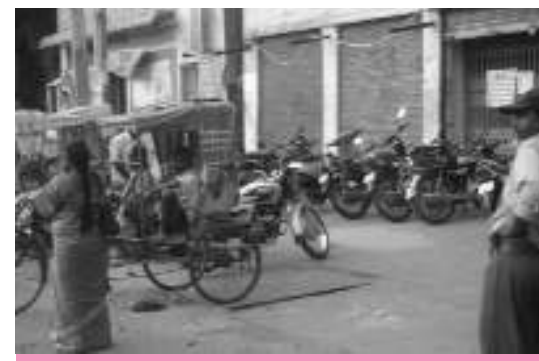


"The counselor said that you will die in a year. I said I am using medicines and spending Rs 3000 per month. He said it is just wasting your money. Whatever you do you will die in one year."

(25 year old, HIV-positive sex worker)

One of the sex workers mentioned that she was taking ART and received a months' supply of medicines from the hospital in the other town but discontinued them after she felt better. She mentioned that the provider did not give her any advice about the treatment in terms of taking it lifelong and that she should return to the centre for her medicines.

"I was given medicines for a month now I am feeling better and so did not go again. No one told me to come back..."

(30 year old, HIV-positive sex worker)

\section{Violence and alcohol use emerge as key riskfactors in sexworkers' lives}

A significant proportion of the brothel-based and mobile sex workers reported that they have experienced violence in the course of their work. One-half mentioned that they were beaten and slapped, one-fourth mentioned they were forced to have sex with one person and one-fifth reported that they were forced to have sex with more than one person. In most of these cases the perpetrator was the customer followed by rowdies and then the police. The reason for this violent response from the customer was because the sex workers had insisted on the use of the condom against the wish of the customer.

Alcohol use was mentioned by over two-thirds of the sex workers. The majority of these sex workers mentioned they drank daily while one-third said every week. A significant proportion of the sex workers mentioned they drank with their customers followed by their own friends. The common reasons for drinking alcohol were to release mental and physical stress, to 'give company' to their customers and to enhance sexual performance. When asked about use of condoms after frequent consumption of alcohol in a day, almost all the sex workers said they always use condoms, even when they have had drinks.

\section{Discussion}

Sexual health of sex workers has been addressed by
HIV programs as risk prevention by narrowly focusing on condom use with clients. This study highlights the need to promote condom use in intimate relations with lovers and husbands as well as to address sexual health with the perspective of sexual pleasure and fulfilment. Also, the focus on prevention of sexually transmitted infections has warranted ignoring other sexual health and gynaecological problems that sex workers may suffer from. The data indicates that sex workers report multiple signs and symptoms of reproductive morbidity and need to be provided with care and treatment for the same.

While the respondents recruited for the study were in their late 20s and early 30s, it is evident that women marry young and have multiple pregnancies at an early age. It is imperative that NGOs working with sex workers need to make concerted efforts to enrol younger sex workers in their programs and provide them or refer them to services for reproductive care including PPTCT services. Also, as one-third of the sex workers report they have their deliveries at home, programs should ensure that trained birth attendants and nursing care is available to them as well as PPTCT services, if required. For the majority of sex workers who had undergone sterilization, condom use should also be promoted as a dual method to protect against infections.

As a majority of sex workers report accessing HIV voluntary counselling and testing services, these should serve as an entry point to link the HIVpositive sex workers to care and treatment services. Linkages between PPTCT and ART centres and NGOs working with sex workers need to be strengthened so that sex workers receiving these services can be followed-up to ensure there is no drop-out due to inaccurate information or problems in accessing services. Also, other risk factors such as sexual violence and alcohol use need to be recognized as having an impact on safe sex and condom use and should be addressed through HIV prevention efforts.

The study indicates the need to address sex workers' sexual and reproductive health needs and strengthen linkages with HIV prevention, treatment and care in order to provide comprehensive care to them as women and not just as 'target' population for HIV prevention efforts.

\section{(2) Population Council}

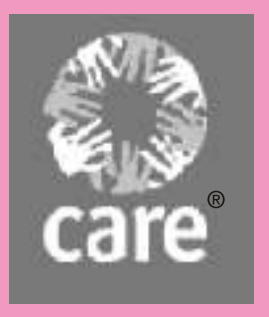

For further information please contact:

Population Council

142 Golf Links (First Floor)

New Delhi 110003, India

Tel.: 91-11-4174 3410/11

Fax: 91-11-4174 3412

Email: info-india@popcouncil.org

\section{www.popcouncil.org}

\section{Contributors}

Vaishali Sharma Mahendra, Sushma Mehrotra, B. Srikanthi, Sucheta Panda, Avina Sarna,

A.K. Jayasree, Rajendra Prasad and Naomi Rutenberg

\section{Donor}

Department for International

Development, U.K.

\section{References}

1. WHO/UNFPA/UNAIDS/IPPF 2005. Sexual and Reproductive Health and HIV/AIDS: A Framework for Priority Linkages.

Suggested citation

Mahendra, V.S., S. Mehrotra, B. Srikanthi, S. Panda, A. Sarna, A.K. Jayasree, R. Prasad and N. Rutenberg. 2007. 'Identifying areas for linkages between HIV and SRH for vulnerable populations: An exploratory study to assess female sex workers' sexual and reproductive health needs' Research Update. Population Council, New Delhi 